appreciably and if a reduction in intake is not advised then weight increase is likely, for diabetic patients do not appear to compensate by an increase in the thermic response to a meal and noradrenaline stimulation. It is therefore interesting that after a mean of 5.3 months of continuous subcutaneous insulin infusion our subjects gained an average of $3 \cdot 5 \mathrm{~kg}$.

We thank all our volunteers, Dr Iain Crombie and Mr Simon Ogston for statistical advice, Ms Maureen Hughes and Miss Shirley Dryden for expert typing, and Dr A McCuish (Glasgow Royal Infirmary) for measuring C peptide values. We also thank the MRC Dunn Nutrition Unit, Cambridge, and $\mathrm{Mr}$ R Rimmer and his colleagues at Ninewells Hospital for advice and help with calorimeter construction. The project was supported by a gran from the Scottish Home and Health Department, which also supported PL, and also from Nordisk UK. PI was supported by a grant from Birthright. A grant from Tenovus, Scotland, provided most of the continuous subcutaneous insulin infusion pumps used in this project, while maintenance of these pumps was aided by some cannulas and syringes from Travenol and a grant from the Tayside Health Board's research committee.

\section{References}

1 Rothwell NJ, Stock MJ. A role for insulin in the diet-induced thermogenesis of cafeteria fed rats. Metabolism 1981;30:673-8.

2 Felig P. Hypothesis; insulin is the mediator of feeding-related thermogenesis; insulin resistance and/or deficiency results in thermogenic defect which contributes to the pathogenesis of obesity. and/or deficiency results in ther

3 Golay A, Schutz Y, Mever HU, et al. Glucose induced thermogenesis in nondiabetic and diabetic obese subjects. Diabetes 1982;31:1023-8.

4 Ravussin E, Acheson KJ, Vernet $O$, Danforth E, Jequier E. Absence of a thermogenic defect in response to glucose/insulin infusion in human obesity and type II diabetics. In: Garrow JS Halliday D, eds. Substrate and energy metabolism in man. London: Libbey, 1985:A19.

5 Home PD, Capaldo B, Burrin JM, Worth R, Alberti KGMM. A crossover comparison of continuous subcutaneous insulin infusion (CSII) against multiple injections in insulindependent diabetic subjects. Improved control with CSII. Diabetes Care 1982;5:457-65.

6 Royal College of Physicians of London. Obesity. F R Coll Physicians Lond 1983;17:4-6.

7 Metropolitan Life Insurance Company. Morbidity among overweight men and women. Statistical Bulletin 1980;41(Feb):6.
8 Weir JBD. New methods for calculating metabolic rate with special reference to protein metabolism. 7 Physiol (Lond) 1949;109:1-9.

.

9 Booth NM, Sadford I. Normp Jung RT, Shetty PS, James WPT, Barrand MA, Callingham BA. Reduced thermogenesis in obesity. Nature 1979;279:322-3.

11 Trinder P. Determination of blood glucose using an oxidase-peroxidase system with a non- $C$ carcinogenic chromogen. $f$ Clin Pathol 1969;23:158-6

12 Chromy N, Bergel J, Voznicek J, Kromholzova L, Musil J. Assay of serum free fatty acids by extraction photometric procedure. Clin Chim Acta 1977;80:327-32.

13 Menard LA, Dempsey ME, Blankstem LA, Aleyassine H, Wachs M, Soeldner JS. Quantitative J determination of glycosylated hemoglobin $A_{1}$ by agar gel electrophoresis. Clin Chem 1980;26: 1598-1603.

14 Gin H, Messerchmitt C, Brother E, Aubertin J. Metformin improved insulin resistance in type I insulin-dependent diabetic patients. Metabolism 1985;34:923-5.

15 Jequier E. Energy expenditure in obesity. Clin Endocrinol Metab 1984;13:563-80.

16 Nair KS, Halliday D, Garrow JS. Increased energy expenditure in poorly controlled type I (insulin 1984;27:13-6.

17 Nair KS, Garrow JS, Ford C, Mahler RF, Halliday D. Effect of poor diabetic control and obesity on whole body protein metabolism in man. Diabetologia 1983;25::400-3.

18 Welle S, Campbell RG. Stimulation of thermogenesis by carbohydrate overfeeding. 7 Clin Invest 1983;71:916-25.

19 Norgan NG, Durnin JVGA. The effect of 6 weeks of overfeeding on the body weight, body composition and energy metabolism of young men. Am f Clin Nutr 1980;33:978-88.

20 Dallosso HM, James WPT. Whole body calorimetry studies in adult man. Effect of fat overfeeding on 24 hr energy expenditure. Br $\mathcal{F}$ Nutr 1984;52:49-64.

21 Cunningham S, Leslie $\mathrm{P}$, Hopwood D, et al. The characterisation and energetic potential of brown adipose tissue in man. Clin Sci 1915;69:343-8.

22 Astrup A, Bulow J, Madsen J, Christensen NJ. Contribution of BAT and skeletal muscle to thermogenesis induced by ephedrine in man. Am f Physiol 1985;248:E507-15.

23 Havel RJ, Carlson LA, Ekelurd L-G, Holmgren A. Studies on the relation between mobilisation of free fatty acids and energy metabolism in man; effects of norepinephrine and nicotinic acid. Metabolism 1964;13:1402-11.

24 Simonson DC, Tamborlane WV, Sherwin RS, Smith JD, DeFronzo RA. Improved insulin sensitivity in patients with type I diabetes mellitus after CSII. Diabetes 1985/34(suppl 3):80-6. 1962;16:129-32.

26 Illingworth PJ, Jung RT, Howie PW, Leslie P, Isles TE. A diminution in energy expenditure during lactation. Br Med f 1986;292:437-41.

27 Morgan JB, York DA, Wasilewska A, Portman J. A study of the thermic responses to a meal and to a sympathomimetic drug (ephedrine) in relation to energy balance in man. $\mathrm{Br} f \mathrm{Nutr}$ 1982;47: $\overrightarrow{\mathrm{N}}$ 21-32.

28 Finer N, Swan PC, Mitchell FT. Suppression of norepinephrine-induced thermogenesis in human obesity by diet and weight loss. Int $\mathcal{F}$ Obes 1985;9:121-6.

29 Astrup A, Lundsgaard C, Madsen J, Christensen N]. Enhanced thermogenic responsiveness during chronic ephedrine treatment in man. Am f Clin Nutr 1985;42:83-94.

Accepted 20 August 1986

\title{
Detection of spread of malignant lymphoma to the liver by low field strength magnetic resonance imaging
}

\author{
M A RICHARDS, J A W WEBB, \\ R H REZNEK, \\ G DAVIES, \\ S E JEWELL, \\ W S SHAND, \\ P F M WRIGLEY, T A LISTER
}

\begin{abstract}
The accuracy of spin lattice relaxation time $\left(T_{1}\right)$ measurement obtained with a low field strength magnetic resonance imager for the detection of spread of malignant lymphoma to the liver was assessed. The results of histological examination obtained at open liver biopsy were compared with liver $T_{1}$ values in 27 patients with lymphoma. The normal range for $T_{1}$ was estab-
\end{abstract}

St Bartholomew's Hospital, London EC1A

M A RICHARDS, MB, MRCP, Imperial Cancer Research Fund department of medical oncology

J A W WEBB, MD, FRCR, department of radiology

R H REZNEK, MRCP, FRCR, department of radiology

G DAVIES, MS, FRCS, department of surgery

S E JEWELL, HDCR (R), department of radiology

W S SHAND, MD, FRCS, department of surgery

P F M WRIGLEY, PHD, FRCP, Imperial Cancer Research Fund department of medical oncology

T A LISTER, MD, FRCP, Imperial Cancer Research Fund department of medical oncology

Correspondence to: Dr Lister. lished by scanning 61 healthy volunteers. Magnetic resonance imaging was highly sensitive in detecting hepatic lymphoma, all seven patients with liver lymphoma proved by biopsy having considerably higher $T_{1}$ values. Specificity was less good. Five out of 20 patients with no histological evidence of hepatic lymphoma had abnormal $T_{1}$ values.

This level of sensitivity is considerably better than that $\mathscr{N}$ reported for other imaging methods and contrasts with the results of one previous study using a different magnetic resonance system. Low field strength magnetic resonance imaging may $\tilde{N}$ prove to be a useful screening test in patients with lymphoma. The presence of a normal liver $T_{1}$ seems to be a reliable guide to the absence of hepatic disease.

\section{Introduction}

Accurate diagnosis of spread of disease to the liver in patients with malignant lymphoma is important for selecting treatment and $\stackrel{\mathbb{Q}}{\varrho}$ determining prognosis. Clinical assessment of liver disease is notoriously inaccurate; hepatomegaly is an unreliable guide to the presence of lymphoma, ${ }^{12}$ raised serum alkaline phosphatase activities may be found when the results of liver biopsies are normal, ${ }^{2}$ 
BRITISH MEDICAL JOURNAL VOLUME 2931 NOVEMBER 1986

and, conversely, hepatic lymphoma may occur when the alkaline phosphatase activity is normal. ${ }^{4}$

The sensitivity of imaging methods in the detection of liver lymphoma is poor, mainly because infiltration by lymphoma is usually diffuse rather than focal. Zornosa and Ginaldi obtained a sensitivity of only $57 \%$ for the detection of spread to the liver using computed tomography in a study of 65 patients with lymphoma, and similarly disappointing results have been reported for radionuclide scanning. ${ }^{56}$ Although no large series on ultrasound have been published, this method is also considered to be a poor detector of diffuse liver lymphoma. ${ }^{78}$

We undertook this study to determine the accuracy of the measurement of spin lattice relaxation time $\left(T_{1}\right)$ with a low field strength magnetic resonance imager in detecting liver lymphoma.

\section{Patients and methods}

We studied 27 patients with malignant lymphoma (18 with Hodgkin's disease and nine with non-Hodgkin's lymphoma) aged 18-81 years (median 41) for whom the histological findings of open liver biopsy were available.

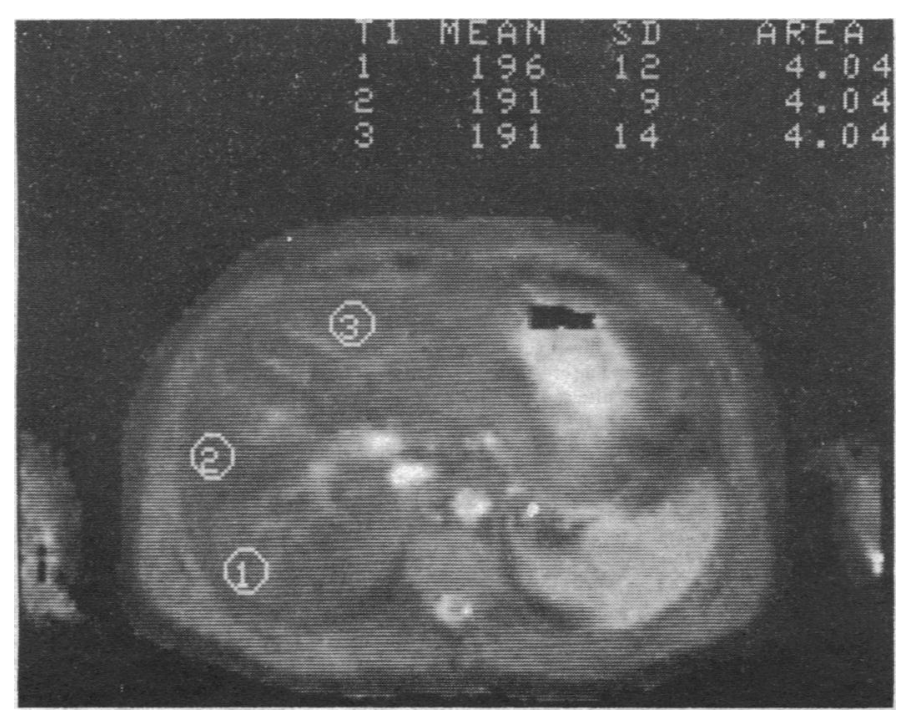

FIG 1-Calculated $T_{1}$ image of an axial section through the upper abdomen of a volunteer. Cursors are placed peripherally over the liver to avoid major vessels.

Twenty six underwent laparotomy with wedge liver biopsy and in one case tissue was obtained at necropsy. Five patients underwent laparotomy for diagnostic reasons (one with Hodgkin's disease, four with non-Hodgkin's lymphoma), 12 for pretreatment staging (all with Hodgkin's disease), three for post-treatment reassessment (all with Hodgkin's disease), and six for therapeutic reasons (one with Hodgkin's disease, five with non-Hodgkin's lymphoma). Magnetic resonance imaging was performed within two weeks of the histological assessment in all cases, and no treatment was given during this period. Magnetic resonance imaging preceded histological assessment in 20 cases and was performed after laparotomy in seven. Sixty one healthy volunteers ( 33 men and 28 women), age range 21-60 years, also underwent scanning to establish a normal range of liver $T_{1}$. Liver $T_{1}$ values for the 27 patients were compared with the histological findings and with the $T_{1}$ values for the volunteers.

Axial sections $16 \mathrm{~mm}$ thick were obtained through the liver in all patients using a 0.08 tesla MD 800 resistive magnetic resonance scanner, operating at $3.4 \mathrm{MHz}$. At least four axial sections were obtained for each normal subject.

We used the standard pulse sequence for this scanner. ${ }^{9}$ This consists of alternating saturation recovery and inversion recovery sequences with a repetition time of $1000 \mathrm{~ms}$ and an inversion time of $200 \mathrm{~ms}$. A calculated $T_{1}$ image is generated from a computed algorithm. $T_{1}$ is measured by placing a cursor over a $4 \mathrm{~cm}^{2}$ region of interest (fig 1 ). A minimum of 12 readings (three from each of four slices) were taken for each study and the mean $T_{1}$ calculated. Care was taken to avoid measuring areas containing hepatic or portal veins. Reproducibility of $T_{1}$ measurement was assessed by scanning a standard phantom over three months, which is reported elsewhere ${ }^{10}$ In the relevant range for the liver the standard deviation of measurements was less than $2 \%$ of the mean.

\section{Results}

Figure 2 shows the liver relaxation times for patients and volunteers. Mean relaxation times for the 61 healthy volunteers ranged from 166 to $222 \mathrm{~ms}$ (mean (SD) 191 (13) ms).

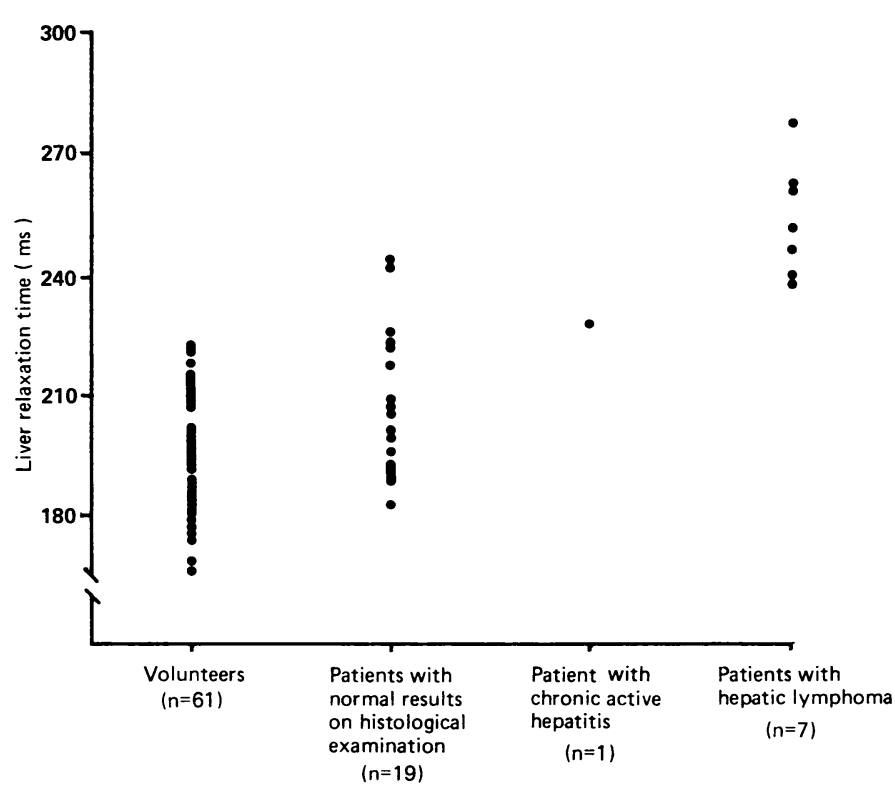

FIG 2-Mean liver $T_{1}$ values for patients with lymphoma and volunteers.

Seven patients (five with non-Hodgkin's lymphoma, two with Hodgkin's disease) showed histological evidence of spread of the lymphoma to the liver. All of these had noticeably longer mean relaxation times $(>3 \mathrm{SD}$ above the normal mean), range $238-278 \mathrm{~ms}$. All seven showed increased $T_{1}$ throughout the liver, but with additional focal lesions with even higher $T_{1}$ values in one case.

Nineteen patients yielded normal results on liver biopsy. Fifteen of these had liver $T_{1}$ values within the normal range established by this study. Two of the other four patients showed a slightly higher $T_{1}(223$ and $226 \mathrm{~ms})$ and two had noticeably longer times ( 241 and $243 \mathrm{~ms}$ ). Biopsy specimens from the liver of the remaining patient showed chronic active hepatitis but no evidence of hepatic lymphoma. The patient's serum was positive for hepatitis B surface antigen. His liver $T_{1}$ was slightly increased $(228 \mathrm{~ms})$.

Twelve patients therefore had liver relaxation times outside the normal range for the healthy volunteers. Seven of these had hepatic lymphoma confirmed by biopsy, one had chronic active hepatitis, and four yielded normal biopsy specimens. $T_{1}$ was considerably longer in most patients with hepatic lymphoma than in those who yielded negative results on liver biopsy (fig 2). Two patients in whom histological examination of the liver yielded normal results, however, had $T_{1}$ values within the range for patients with hepatic lymphoma.

The patients with normal results of histological examination had liver $T_{1}$ values around $15 \mathrm{~ms}$ longer than the volunteers (fig 2 ). This difference was highly significant (Student's $t$ test $=4 \cdot 12, \mathrm{p}<0 \cdot 0001$ ) and remained significant when the two patients in this group with considerably higher liver $T_{1}$ values were excluded from the analysis $(p<0 \cdot 001)$.

\section{Discussion}

These findings indicate that measurement of $T_{1}$ by this low field strength magnetic resonance imager is a very sensitive detector of 
liver lymphoma. Magnetic resonance imaging missed none of the seven patients with hepatic lymphoma confirmed by biopsy despite the fact that six patients had only diffuse disease. Furthermore, the relaxation times of the patients with proved hepatic lymphoma were more than three standard deviations above the normal mean.

The high level of sensitivity found in this study contrasts with the results from the only other study of magnetic resonance imaging in the detection of hepatic lymphoma, which was performed by Weinreb et al using a 0.35 tesla magnetic resonance imager. ${ }^{10}$ Twelve of their 13 patients with histologically proved lymphoma had mean liver $T_{1}$ values within one standard deviation of the normal mean established in the study. As $T_{1}$ varies with magnetic field strength absolute times reported from centres using different imagers may be expected to differ. The range of liver relaxation times for the 20 normal subjects in the study by Weinreb et al (195$1112 \mathrm{~ms}$ ) was relatively much wider than that found in this study. This discrepancy has not been explained but may reflect the differences in the pulse sequence and in the method of calculating $T_{1}$. The technique of adiabatic fast passage in the inversion recovery sequence used in our type of scanner is said to give very accurate measurements, ${ }^{11}$ and we have verified their reproducibility. ${ }^{12}$ Weinreb et al used spin echo sequences with long and short repetition rates to calculate $T_{1}$. The lower magnetic field strength used in our study may also be important; differences between the $T_{1}$ values of normal and malignant tissues may be greatest at lower magnetic field strengths. ${ }^{13}{ }^{14}$ It is unlikely that differences between the populations of patients or volunteers in the two studies could have accounted for the pronounced difference in the results.

Although we found liver $T_{1}$ to be highly sensitive to spread of lymphoma, the specificity of this measurement was less good. Five of the patients who had higher $T_{1}$ values did not have hepatic lymphoma. One of these patients had chronic active hepatitis, which is known to produce higher $T_{1}$ values. ${ }^{15}$ The explanation for the remaining four patients (two with slightly higher $T_{1}$ values and two with considerably higher values) is unknown. It seems unlikely, though possible, that these represent false negative results of liver biopsies. Although it is recognised that lymphoma may frequently be missed by percutaneous liver biopsy, the incidence of positive results of biopsies is higher at peritoneoscopy and further increased by open wedge biopsy. ${ }^{16}$ Open liver biopsy is thus the best available method for detecting hepatic lymphoma (albeit the most invasive) and was therefore used as the yardstick in this study.

The difference between the results for healthy volunteers and for the group of patients with normal results of histological examination was unexpected. Although most of the patients (15 of 19) with normal liver biopsy specimens had liver $T_{1}$ values within the normal range, the patients as a group had significantly longer times than the volunteers. This may be because of a non-specific hepatic response to the presence of lymphoma elsewhere, as has been suggested by Bagley et al as the cause of false positive alkaline phosphatase measurements. ${ }^{3}$ The four patients with liver $T_{1}$ values outside the normal range but with normal results on histological examination may be the most pronounced examples of this phenomenon. In this study the increase in liver $T_{1}$ was generally less among those with $\underline{T}$ negative results on biopsy than among those with positive results. Further evaluation is needed to establish whether there is a level of liver $T_{1}$ above which histological evidence of lymphoma is found in $c$ all cases.

These results, showing a higher level of sensitivity than has been observed with any other imaging method, suggest that measurement of liver $T_{1}$ by low field strength magnetic resonance imaging $\&$ may be a useful non-invasive screening test in patients with lymphoma. As Castellino pointed out, in patients with a disease where the overall incidence of hepatic disease is low the sensitivity is the most important index by which to judge a technique. ${ }^{17}$ If the results obtained in this study are confirmed low field strength magnetic resonance imaging may prove to be a reliable method for excluding hepatic lymphoma. Invasive biopsy procedures might then be reserved for those patients with higher $T_{1}$ values, for whom a definite diagnosis of liver disease is clinically important.

We thank Dr A G Stansfeld for reviewing all the histology and Mr W M Gregory for his help with the statistical analysis. We are grateful to the Joint Research Board of St Bartholomew's Hospital and to the Jameel Research Fund for financial support.

\section{References}

1 Rosenberg SA, Diamond HD, Jaslowitz B, Craver LF. Lymphosarcoma: a review of 1269 cases. Medicine (Baltimore) 1961;40:31-84.

2 Hermreck AS, Kofander VS, Bell C. The staging of Hodgkin's disease; preoperative clinical assessment versus operative evaluation. Am f Surg 1975;130:639-42.

3 Bagley CM, Roth JA, Thomas LB, DeVita VT. Liver biopsy in Hodgkin's disease: clinicopathologic correlations in 127 patients. Ann Intern Med 1972;76:219-25.

4 Goffinet DR, Castellino RA, Kim H, et al. Staging laparotomies in unselected previously untreated patients with non Hodgkin's lymphomas. Cancer 1973;32:672-81.

5 Zornosa J, Ginaldi S. Computed tomography in hepatic lymphoma. Radiology 1981;138:405-10. 6 Lipton MJ, DeNardo GL, Silverman S, Glatstein E. Evaluation of the liver and spleen in Hodgkin's disease. I: the value of hepatic scintigraphy. Am $\mathcal{J}$ Med 1972;52:356-61.

Carroll BA, Ta HN. The ultrasonographic appearance of extranodal lymphoma. Radiolog 1980;136:419-25.

8 Cosgrove DO, McCready VR. Ultrasound imaging: liver, spleen, pancreas. Chichester: John Wiley, 1982:176.

9 Eastwood L. Nuclear magnetic resonance proton imaging. In: Dendy PP, Ernst DW, Sengun A eds. Technical advances in biomedical physics. The Hague: Martinus Nijhoff, 1984:377-410.

10 Weinreb JC, Brateman L, Maravilla KR. Magnetic resonance imaging of hepatic lymphoma. Am J Radiol 1984;143:1211-4.

11 Redpath TW. Calibration of the Aberdeen NMR imager for proton spin-lattice relaxation time measurements in vivo. Phys Med Biol 1982;27:1057-65.

12 Richards MA, Gregory WM, Webb JAW, Jewell SE, Reznek RH. Reproducibility of spin lattice relaxation time ( $\mathrm{Tl}$ ) measurement using an 0.08 tesla magnetic resonance imager. $\mathrm{Br}$ f Radiol (in press).

13 Damadian R, Zaner K, Hor D, DiMaio T, Minkoff L, Goldsmith M. Nuclear magnetic resonance as a new tool in cancer research: human tumors by NMR. Ann NY Acad Sci 1973;222:1048-76.

Diegal JG, Pintar MM. A possible improvement in the resolution of proton spin relaxation for the study of cancer at low frequency. Fournal of the National Cancer Institute 1975;55:725-6.

15 Cherryman GR, Smith FW, Bayliss AP, et al. NMR in parenchymal liver disease. Proceedings of the Society of Magnetic Resonance in Medicine 1985;2:1137-8.

16 Chabner BA, Johnson RE, Chretien PB, et al. Percutaneous liver biopsy, peritoneoscopy and laparotomy: an assessment of the relative merits in the lymphomata. Br 7 Cancer 1975; and laparotomy:

17 Castellino RA. Imaging techniques for staging abdominal Hodgkin's disease. Cancer Treat Rep $1982 ; 66(4): 697-700$.

Accepted 5 August 1986)

\section{YEARS AGO}

There can certainly be no doubt that the state of the labour-market and the weather has brought many more people face to face with starvation this winter, than for many years past. But still it may be doubted whether they have mastered the use of all weapons of defence against that deadly foe. A valiant vegetarian correspondent, who has never for eight years betrayed his dietary in prosperity or in adversity, writes to us to point out that in vegetarianism lies an escape from some of the pressure of poverty, inasmuch as the healthy vegetarian, in full exercise of his powers, can support himself on $5 \mathrm{~d}$. a day, which may suffice for three meals, such as shall thoroughly fit him for the duties of life. During an eight years' experience of a life of hard work, involving nine or ten, or even twelve hours' work a day, this slender tax has proved sufficient for nutrition. Some details of the mode of its application to the poorest classes are required; and it must not be forgotten that one of the main difficulties which has to be met is the clumsiness in cooking, and almost total absence of kitchen utensils, which obtains among the poor. If they have a frying-pan as well as a kettle, that is all that can be expected; and that increases their tendency to struggle after animal food, expensive though it may be, and, if they cannot get it, to fall back on dry bread with perhaps a dash of treacle, instead of the cheaper and more appetising preparations that can be made from greens, potatoes, lentils, oatmeal, arrowroot, rice, sago, and the like, which need a saucepan, or better still, a stock-pot. Important as it is that they should realise the worth of vegetables, it is almost more important that they should appreciate in the French fashion the value of a pot au feu, and not rank it contemptuously as "slops." There is a great field for instruction in this matter by penny dinners and public kitchens. (British Medical Fournal 1886;i:512.) 